\title{
Erratum to: Effects of polymer-cement ratio and accelerated curing on flexural behavior of hardener-free epoxy-modified mortar panels
}

Muhammad Aamer Rafique Bhutta • Yoshihiko Ohama

Published online: 21 January 2010

(C) RILEM 2010

\section{Erratum to: Materials and Structures DOI 10.1617/s11527-009-9578-8}

Due to an unfortunate turn of events this article has been published with only one author mentioned whereas there should have been mentioned two authors. Please find here the correct list of authors that should be regarded by the reader as the final version.
The online version of the original article can be found under doi:10.1617/s11527-009-9578-8.

\section{A. R. Bhutta (两)}

Department of Structures and Materials Faculty of Civil Engineering, Universiti Teknologi Malaysia, Skudai,

Johor, Malaysia

e-mail: marafique@utm.my

Y. Ohama

Nihon University, Koriyama, Fukushima, Japan 